\title{
Anthropogenic and natural constituents in particulate matter in the Netherlands
}

\author{
E. P. Weijers ${ }^{1}$, M. Schaap ${ }^{2}$, L. Nguyen ${ }^{3}$, J. Matthijsen ${ }^{4}$, H. A. C. Denier van der Gon ${ }^{2}$, H. M. ten Brink ${ }^{1}$, and \\ R. Hoogerbrugge ${ }^{3}$ \\ ${ }^{1}$ Department of Air Quality and Climate Change, Energy research Centre of the Netherlands (ECN), Petten, The Netherlands \\ ${ }^{2}$ TNO, Business unit Environment, Health and Safety, Utrecht, The Netherlands \\ ${ }^{3}$ National Institute for Public Health and the Environment (RIVM), Bilthoven, The Netherlands \\ ${ }^{4}$ Netherlands Environmental Assessment Agency (PBL), Bilthoven, The Netherlands
}

Received: 12 October 2010 - Published in Atmos. Chem. Phys. Discuss.: 5 November 2010

Revised: 24 February 2011 - Accepted: 1 March 2011 - Published: 14 March 2011

\begin{abstract}
To develop mitigation strategies for reducing concentrations of both $\mathrm{PM}_{2.5}$ and $\mathrm{PM}_{10}$, the origin of particulate matter (PM) needs to be established. An intensive, one-year measurement campaign from August 2007 to August 2008 was carried out to determine the composition of $\mathrm{PM}_{10}$ and $\mathrm{PM}_{2.5}$ at five locations in the Netherlands, aiming at reducing the uncertainties on the origin of PM. Generally, a considerable conformity in the chemical composition of $\mathrm{PM}_{2.5}$ (and $\mathrm{PM}_{10}$ ) is observed. From all constituents present in $\mathrm{PM}_{2.5}$, the secondary inorganic aerosol is the most dominant (42$48 \%$ ), followed by the total carbonaceous matter (22-37\%). Contributions from sea salt (maximum 8\%), mineral dust and metals (maximum 5\%) are relatively low. For the first time, a detailed overview of the composition of the coarse fraction can be presented. Compared to the fine fraction, contributions of sea salt, mineral dust and metals are larger resulting in a more balanced distribution between the various constituents. Through mass closure a considerable part of the PM mass could be defined $\left(\mathrm{PM}_{2.5}: 80-94 \%\right)$. The chemical distribution on days with high PM levels shows a distinct increase in nitrate as well as in the unaccounted mass. Contributions of the other constituents remain equal or are lower (sea salt) when expressed in percentages. A correspondence between nitrate and the unaccounted mass is observed hinting at the presence of water on the filters. The contribution from natural sources in the Netherlands (at a rural station) was estimated to be 19 to $24 \%$ for $\mathrm{PM}_{10}$ and 13 to $17 \%$ for $\mathrm{PM}_{2.5}$.
\end{abstract}

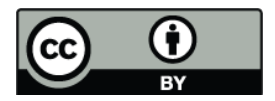

Correspondence to: E. P. Weijers (weijers@ecn.nl)

\section{Introduction}

Although air quality in Europe has improved substantially over the past decades, air pollution still poses a significant threat to human health (EEA, 2007). Health effects of air pollution are dominated by particulate matter, both $\mathrm{PM}_{2.5}$ and $\mathrm{PM}_{10}$. Short-term exposure to PM has frequently been associated with increased human morbidity and mortality (e.g., Brunekreef and Holgate, 2002). Effects of long-term exposure to PM are much more uncertain than the short-term effects, but are believed to have a much greater effect on health loss (Dockery et al., 1993; Pope et al., 1995). Recent estimates arrive at an average loss of life expectancy of about 6-12 months in the Netherlands (EEA, 2007). So far, there is no conclusive evidence which component or components are most relevant for deteriorating human health, although some suggestions have been made, e.g. soot (Hoek et al., 2002). Therefore, the European air quality standards currently focus on $\mathrm{PM}_{10}$ and $\mathrm{PM}_{2.5}$.

At present, many countries in Europe, including the Netherlands, have problems adhering to the daily limit value for $\mathrm{PM}_{10}$ at hotspot locations. In the Directive (2008/50/EC) on ambient air quality and cleaner air for Europe (EU, 2008) new air quality standards for fine particulate matter $\left(\mathrm{PM}_{2.5}\right)$ have been established. An annual mean $\mathrm{PM}_{2.5}$ concentration of $25 \mu \mathrm{g} \mathrm{m}^{-3}$ has been set as target value to be achieved in 2010 and as limit value to be adhered to by 2015 . The new directive introduces additional $\mathrm{PM}_{2.5}$ objectives, that aim to a reduce human exposure to $\mathrm{PM}_{2.5}$. The average exposure indicator (AEI) is a three-year averaged $\mathrm{PM}_{2.5}$ level measured at urban background locations throughout European Member States. A reduction target of $15 \%$ of the AEI between 2010 and 2020 for the Netherlands might be reached under current legislation, whereas a reduction of $20 \%$ is probably

Published by Copernicus Publications on behalf of the European Geosciences Union. 
not even reached with outlined additional measures (Matthijsen et al., 2009). To develop mitigation strategies to meet these targets and to reduce the concentrations of both $\mathrm{PM}_{2.5}$ and $\mathrm{PM}_{10}$ in general one needs to establish the origin of particulate matter. Of particular interest is the quantification of the anthropogenic and natural fractions in PM as these provide an indication of the "playing field" of policy makers.

Important information on the origin of particulate matter can be obtained through chemical analysis to establish its composition (Putaud et al., 2004, 2009; Viana et al., 2008; Sillanpää et al., 2006; Salvador et al., 2007; Mazzei et al., 2008; Almeida et al., 2007). Many components can be used as tracers for specific sources. For example, sodium is a tracer that is almost exclusively associated with sea salt. However, one is usually not able to analyze the full composition and a significant portion of the particulate mass is therefore unknown. Using assumptions on the relationships between (a group of) tracers and major constituents one can attribute the mass to these constituents, the so-called practical chemical mass closure approach (Harrison et al., 2003). In this way an estimate can be derived for the major source contributions to PM. Though this approach significantly reduces the unknown mass a total mass closure is usually not attained. The (relative) magnitude of the unexplained mass is an indicator for the uncertainty in the mass attribution. To independently address such issues one can apply statistical techniques to the observation dataset to address the possible source categories for PM. Techniques such as positive matrix factorization (PMF) can be used to search for groups of components with the same behaviour in time, which are then assumed to derive from a single source or group of similar sources (Hopke et al., 2001). Hence, a mass closure approach as well as PMF will give us independent insights from an empirical point of view in the actual PM sources.

Here, a mass closure approach is used to study the chemical composition of $\mathrm{PM}_{10}$ and $\mathrm{PM}_{2.5}$ filter samples that were collected in the Netherlands at five measurement sites for a period of one year. The study was executed within the framework of the Policy-Oriented Research Program (BOP) and described in detail by Schaap et al. (2010). The general aim of the national BOP program was to reduce knowledge gaps about composition, distribution and origin of particulate matter in the Netherlands. This study establishes the chemical composition measured at Dutch rural and urban locations. Properties of various constituents in fine and coarse matter, respective mass deficits and the changing composition on days with higher PM masses are demonstrated. Also, the contributions of natural material in particulate matter and political implications are discussed. The usefulness of the PMF approach is demonstrated elsewhere (Mooibroek et al., 2010; Schaap et al., 2010) who applied this technique on the same data set.

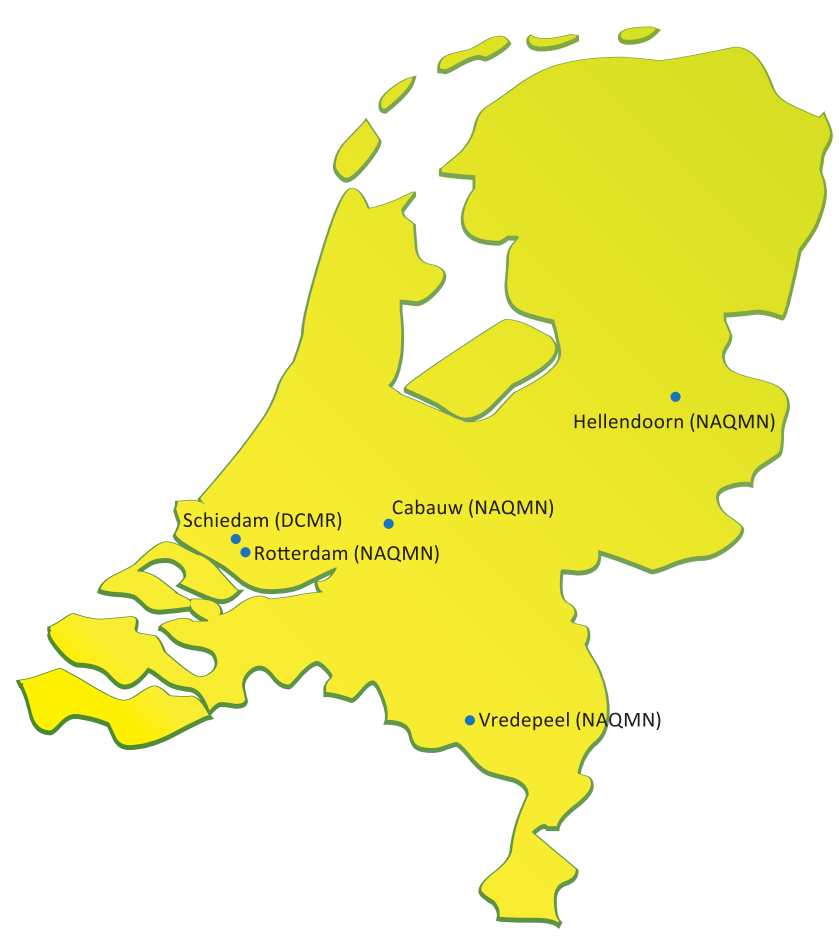

Fig. 1. Localisation of the five BOP measurement sites in the Netherlands.

\section{Experimental methods}

\subsection{Monitoring locations}

Five sites were selected for the monitoring of the $\mathrm{PM}_{10}$ and $\mathrm{PM}_{2.5}$ composition (see Fig. 1). These include three rural background sites: Hellendoorn ( $\sim 150 \mathrm{~km}$ from Rotterdam), Cabauw ( $\sim 50 \mathrm{~km}$ from Rotterdam) and Vredepeel $(\sim 100 \mathrm{~km}$ from Rotterdam). Cabauw represents the rural background for the (industrialised) western part of the country whereas Hellendoorn and Vredepeel were selected to add information from the eastern and southern parts where agriculture dominates. At Vredepeel intensive livestock activity exists in the direct surroundings. Like the rural sites, the urban background location Schiedam belongs to the Dutch National Air Quality Monitoring Network (NAQMN) maintained by RIVM. The kerbside (traffic) site in Rotterdam is part of the air quality network operated by the regional environmental protection agency (DCMR). Further characteristics of these locations are given in Table 1.

\subsection{Measurement strategy}

The filter collection routine $\left(\mathrm{PM}_{10}\right.$ and $\left.\mathrm{PM}_{2.5}\right)$ took place every second day between 15 August 2007 and 4 September 2008. Chemical analysis was done every fourth day. For each of the five sites the following components were determined in the filter samples: sulphate, nitrate, ammonium, elemental and organic carbon, sodium and chloride as 
Table 1. Properties of the measurement locations.

\begin{tabular}{ll} 
Location & Characteristics \\
\hline Cabauw & $\begin{array}{l}\text { Background location in the centre of the Netherlands } \\
\text { Rural surrounding } \\
\text { Some agricultural emissions in the direct surroundings } \\
\text { Urban areas in 20-40 km distance }\end{array}$ \\
\hline Hellendoorn & $\begin{array}{l}\text { Background location in the east of the Netherlands } \\
\text { Rural surrounding } \\
\text { No known anthropogenic emissions nearby }\end{array}$ \\
\hline Vredepeel & $\begin{array}{l}\text { Background location in the southeast of the Netherlands } \\
\text { Rural surrounding } \\
\text { Intensive live stock (pigs) breeding nearby }\end{array}$ \\
\hline Schiedam & $\begin{array}{l}\text { Urban background location in the west of the Netherlands } \\
\text { Part of Rotterdam urban agglomeration (appr. } 600 \text { 000 inhabitants) } \\
\text { Residential areas surrounded by motorways } \\
\text { Close (<5 km) to industrial activity (refineries, oil-industry) and harbour }\end{array}$ \\
\hline Rotterdam & $\begin{array}{l}\text { Traffic location ("kerbside") in the west of the Netherlands } \\
\text { Part of the Rotterdam agglomeration } \\
\text { Less than } 5 \text { m from the kerb; traffic junction at } 80 \text { m with traffic lights } \\
\text { Heavy traffic }\end{array}$ \\
\hline
\end{tabular}

well as the elemental composition. The filters were collected according to the reference method described in the European Standards (EN12341: 1998 and EN14907: 2005). The measurement instrument was the SEQ47/50 (Leckel GmbH, Germany). In the experimental set-up within the BOP program this sequential low-volume system (LVS) used a flow of $2.3 \mathrm{~m}^{3} \mathrm{~h}^{-1}$. Four of these reference samplers were placed at every location for a paired measurement of $\mathrm{PM}_{10}$ and $\mathrm{PM}_{2.5}$. The sampling period per filter is $24 \mathrm{~h}$ and ran from midnight to midnight. All filters were protected during storage and transport. The logistic and operational (QA/QC) procedures were those used in the NAQMN network.

\subsection{Chemical analyses}

Two types of filter media, quartz (QMA) and teflon (PTFE), were used. The teflon filters were chosen to quantify the presence of silicon. The quartz fibre filter media is the material commonly used in gravimetric studies. They were cut into two equal parts for the SIA and EC/OC analyses. The soluble fraction was extracted from the quartz filters by $7 \mathrm{ml}$ deionized distilled water and kept for $8 \mathrm{~h}$ in a sealed tube $(10 \mathrm{ml})$. Ammonium was then analysed on the AMFIA system (AMmonia Flow Injection Analyser, a flow injection system built at ECN). The system is based on the selective diffusion of $\mathrm{NH}_{4}^{+}$at reduced $\mathrm{pH}$ by conductivity. The detection level is $0.2 \mu \mathrm{g}$ per filter. Sulphate and nitrate were measured in aqueous solutions with the Dionex IC25 ion chromatograph. Detection level is $0.7 \mu \mathrm{g}$ per filter.
The analysis of carbon is based on thermography (Cachiermethod). The filter-sample is heated in an oven resulting in the release of carbon. For quantitative determination of the amount of released carbon the evolved gases are oxidised to $\mathrm{CO}_{2}$ in a post-combustor oven. The discrimination of carbon in OC and EC is operationally defined. OC is the carbon released during the 1 st step $\left(8 \mathrm{~min}\right.$ at $\left.340^{\circ} \mathrm{C}\right)$; the remainder gives an estimate for EC after combustion for $6 \mathrm{~min}$ at $750{ }^{\circ} \mathrm{C}$. The analysis occurs in a Coulomat 702, manufactured by JUWE (Viersen, Germany). The total amount of carbon, $\mathrm{TC}$, is directly proportional to the total amount of $\mathrm{CO}_{2}$ produced. The detection system, in principle, is an absolute method. Monthly calibrations with a standard were performed. Cleaning of the instrument occurred once a month (after a full month of operation). Several samples were in the oven for a longer period and also at a higher temperature to check for complete combustion and proper assessment of the EC. The lower detection limit of the method was around $5 \mu \mathrm{g}$ per filter corresponding to a concentration of $0.1 \mu \mathrm{g} \mathrm{m}^{-3}$. An average experimental blank of $1.2 \mu \mathrm{gOC} \mathrm{m}^{-3}$ was found during the campaign (Ten Brink et al., 2009) consisting of a filter blank of $0.5 \mu \mathrm{g} \mathrm{m}^{-3}$, and a field blank of $0.7 \mu \mathrm{g} \mathrm{m}^{-3}$ (due to gas adsorption on the filter material). As the latter contribution ordinarily occurs in routine PM determination following the reference method, we only subtracted the filter blank from the measured $\mathrm{OC}$ values.

A selection of 28 metals was analysed with Inductively Coupled Plasma-Mass Spectrometry (ICP-MS) after microwave digestion of the Teflon filters with a nitric acid/ $\mathrm{H}_{2} \mathrm{O}_{2}$ mixture (Na, Mg, Al, Si, P, K, Ca, Ti, V, Cr, Mn, Fe, Co, Ni, 
$\mathrm{Cu}, \mathrm{Zn}, \mathrm{Pb}$, As, Ba, Se, Sr, Y, Mo, Cd, Sn, Li, Be). ICP-MS is the standard operational technique in NAQMN. To account for the non-complete dissolution of several metals (e.g. Si, Al) using this digestion method, average correction factors established in a comparison to digestion with HF were used (Schaap et al., 2010). The sum of these elements (with the exception of sodium) is denoted by "total metals".

\subsection{Data handling}

For each site only filter samples were included with a complete characterization. Completeness was interpreted rather strict: if one of the components were missing the entire sample was excluded. As a consequence, the number of samples at a site available for interpretation differ from site to site varying from 26 (Cabauw) to 38 (Hellendoorn). The selected filter data lie within the period January-August 2008. The composition of the coarse fraction was obtained by subtracting the concentrations in the $\mathrm{PM}_{2.5}$ sample from those in $\mathrm{PM}_{10}$ followed by the calculation of the averages and standard deviations. Next, the mass concentrations of all the components were summated and compared with the weighted mass to establish the "not-analysed" part (further denoted by "NA").

\section{Results}

\subsection{Chemical composition}

The average $\mathrm{PM}$ concentrations in our data set are $22.1 \mu \mathrm{g} \mathrm{m}^{-3}\left(\mathrm{PM}_{10}\right), 14.8 \mu \mathrm{g} \mathrm{m}^{-3}\left(\mathrm{PM}_{2.5}\right)$ and $7.3 \mu \mathrm{g} \mathrm{m}^{-3}$ $\left(\mathrm{PM}_{10-2.5}\right)$ indicating that $\mathrm{PM}_{2.5}$ is around two-third of $\mathrm{PM}_{10}$ which is common in the Netherlands. As expected, levels appear highest at the Rotterdam kerbside and lowest at rural Hellendoorn. The mass difference for $\mathrm{PM}_{10}$ between these sites is considerable (near $9 \mu \mathrm{g} \mathrm{m}^{-3}$ ) and originating from nearly equal increments of the fine and coarse mass (4-5 $\left.\mu \mathrm{g} \mathrm{m}^{-3}\right)$.

The average composition of the daily $\mathrm{PM}_{10}$ and $\mathrm{PM}_{2.5}$ filter samples is presented in Fig. 2 and summarised in Table 2. An example of the compositional distribution can be seen in Fig. 3 (Schiedam). Figure 2 directly shows that similarity exists in the chemistry of PM at the various locations. The largest contributions come from nitrate. The concentrations of the "not-analysed" (NA) part in the various fractions is at least of similar level. The only exception is, not unexpectedly, observed at the kerbside location (Rotterdam) where comparable quantities of carbon in the fine fraction and (summated) metals in the coarse fraction were found. This is explained by the emissions from traffic passing nearby. At the other sites the next important component in $\mathrm{PM}_{2.5}$ (and $\mathrm{PM}_{10}$ ) is sulphate, followed by elemental carbon, and, in various order, organic carbon, ammonium, total metals, chloride and sodium. The major parts of the inorganic components, elementary and organic carbon, and NA are in
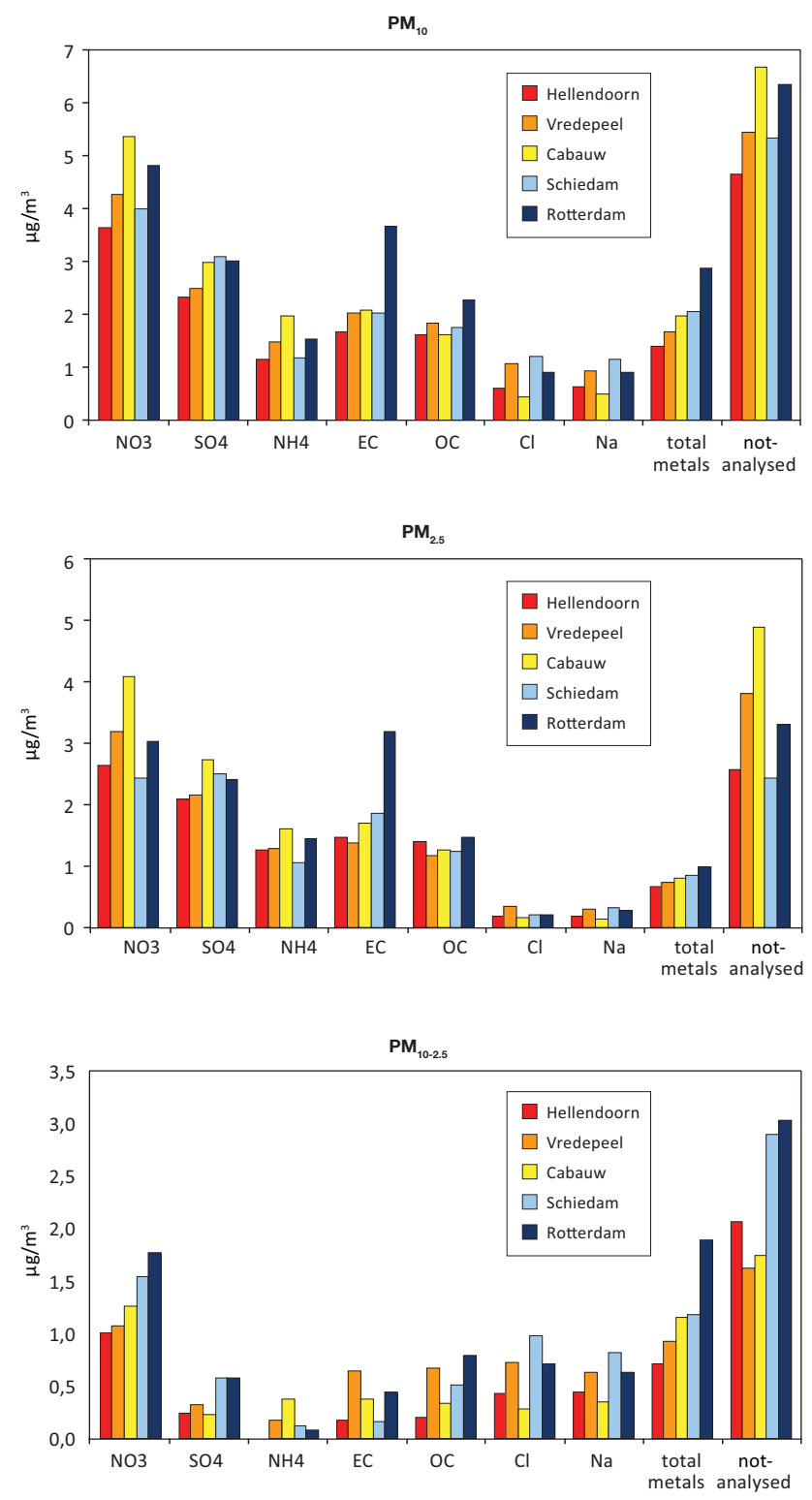

Fig. 2. Absolute concentrations at the five sites.

the fine fraction. Contributions of metals and sea-salt related components (sodium and chloride) mainly arrived from the coarser-sized particles. Notable is further the spatial similarity of the nitrate and ammonium levels with those of the not-analysed part at the five sites. In particular, this is seen in the $\mathrm{PM}_{2.5}$ data and suggests a common origin.

At the two urban sites (Schiedam and Rotterdam) nitrate appeared as one of the more important components within $\mathrm{PM}_{10}$ with levels near or above $4 \mu \mathrm{g} \mathrm{m}^{-3}$. Considerable part of this was in the coarse fraction $\left(1.5\right.$ and $1.8 \mu \mathrm{g} \mathrm{m}^{-3}$, respectively). A similar pattern was seen for sulphate but with lower concentrations. Somewhat surprisingly, the highest nitrate, ammonium and sulphate concentrations occurred in the $\mathrm{PM}_{2.5}$ mass collected at Cabauw. These were even higher 
Table 2. Average concentrations (with standard deviations) of the main components as measured at the five BOP-sites.

\begin{tabular}{|c|c|c|c|c|c|}
\hline number of samples & $\begin{array}{r}\text { Hellendoorn } \\
38\end{array}$ & $\begin{array}{r}\text { Vredepeel } \\
35\end{array}$ & $\begin{array}{r}\text { Cabauw } \\
26\end{array}$ & $\begin{array}{r}\text { Schiedam } \\
33\end{array}$ & $\begin{array}{r}\text { Rotterdam } \\
41\end{array}$ \\
\hline $\mathrm{PM}_{10}$ & $17.7 \pm 6.4$ & $21.2 \pm 7.3$ & $23.6 \pm 11.9$ & $21.8 \pm 9.6$ & $26.3 \pm 11.6$ \\
\hline $\mathrm{NO}_{3}$ & $3.6 \pm 2.1$ & $4.3 \pm 2.2$ & $5.4 \pm 3.7$ & $4.0 \pm 3.6$ & $4.8 \pm 4.2$ \\
\hline $\mathrm{SO}_{4}$ & $2.3 \pm 1.0$ & $2.5 \pm 1.1$ & $3.0 \pm 1.4$ & $3.1 \pm 1.6$ & $3.0 \pm 1.6$ \\
\hline $\mathrm{NH}_{4}$ & $1.2 \pm 0.7$ & $1.5 \pm 1.1$ & $2.0 \pm 1.7$ & $1.2 \pm 1.6$ & $1.5 \pm 1.7$ \\
\hline $\mathrm{EC}$ & $1.7 \pm 1.0$ & $2.0 \pm 0.9$ & $2.1 \pm 1.0$ & $2.0 \pm 1.3$ & $3.7 \pm 1.5$ \\
\hline $\mathrm{OC}$ & $1.6 \pm 1.0$ & $1.8 \pm 0.7$ & $1.6 \pm 0.9$ & $1.8 \pm 1.3$ & $2.3 \pm 1.0$ \\
\hline $\mathrm{Cl}$ & $0.6 \pm 0.9$ & $1.1 \pm 1.2$ & $0.4 \pm 0.4$ & $1.2 \pm 1.3$ & $0.9 \pm 0.9$ \\
\hline $\mathrm{Na}$ & $0.6 \pm 0.6$ & $0.9 \pm 0.8$ & $0.5 \pm 0.4$ & $1.1 \pm 0.8$ & $0.9 \pm 0.6$ \\
\hline total metals & $1.4 \pm 0.8$ & $1.7 \pm 0.7$ & $2.0 \pm 1.2$ & $2.0 \pm 1.0$ & $2.9 \pm 1.1$ \\
\hline not-analysed & $4.6 \pm 3.5$ & $5.5 \pm 2.5$ & $6.7 \pm 4.5$ & $5.3 \pm 2.5$ & $6.4 \pm 3.3$ \\
\hline $\mathrm{PM}_{2.5}$ & $12.5 \pm 5.4$ & $14.5 \pm 6.3$ & $17.5 \pm 11.0$ & $13.0 \pm 7.6$ & $16.4 \pm 10.0$ \\
\hline $\mathrm{NO}_{3}$ & $2.6 \pm 1.7$ & $3.2 \pm 2.3$ & $4.1 \pm 3.7$ & $2.5 \pm 2.5$ & $3.0 \pm 3.0$ \\
\hline $\mathrm{SO}_{4}$ & $2.1 \pm 0.9$ & $2.2 \pm 1.1$ & $2.7 \pm 1.4$ & $2.5 \pm 1.3$ & $2.4 \pm 1.1$ \\
\hline $\mathrm{NH}_{4}$ & $1.3 \pm 0.9$ & $1.3 \pm 1.0$ & $1.6 \pm 1.4$ & $1.1 \pm 1.2$ & $1.4 \pm 1.5$ \\
\hline $\mathrm{EC}$ & $1.5 \pm 0.8$ & $1.4 \pm 0.7$ & $1.7 \pm 0.9$ & $1.9 \pm 1.0$ & $3.2 \pm 1.4$ \\
\hline $\mathrm{OC}$ & $1.4 \pm 0.7$ & $1.2 \pm 0.6$ & $1.3 \pm 0.6$ & $1.2 \pm 0.7$ & $1.5 \pm 0.8$ \\
\hline $\mathrm{Cl}$ & $0.2 \pm 0.2$ & $0.3 \pm 0.4$ & $0.2 \pm 0.1$ & $0.2 \pm 0.2$ & $0.2 \pm 0.2$ \\
\hline $\mathrm{Na}$ & $0.2 \pm 0.2$ & $0.3 \pm 0.3$ & $0.1 \pm 0.1$ & $0.3 \pm 0.2$ & $0.3 \pm 0.3$ \\
\hline total metals & $0.7 \pm 0.4$ & $0.7 \pm 0.2$ & $0.8 \pm 0.3$ & $0.9 \pm 0.3$ & $1.0 \pm 0.3$ \\
\hline not-analysed & $2.6 \pm 2.0$ & $3.8 \pm 2.7$ & $4.9 \pm 5.7$ & $2.4 \pm 2.3$ & $3.3 \pm 3.6$ \\
\hline $\mathrm{PM}_{10-2.5}$ & $5.1 \pm 2.1$ & $6.8 \pm 2.9$ & $6.1 \pm 2.5$ & $8.8 \pm 3.6$ & $9.9 \pm 3.4$ \\
\hline $\mathrm{NO}_{3}$ & $1.0 \pm 0.9$ & $1.1 \pm 1.0$ & $1.3 \pm 2.7$ & $1.5 \pm 1.6$ & $1.8 \pm 1.7$ \\
\hline $\mathrm{SO}_{4}$ & $0.2 \pm 0.4$ & $0.3 \pm 0.5$ & $0.2 \pm 1.1$ & $0.6 \pm 0.8$ & $0.6 \pm 1.0$ \\
\hline $\mathrm{NH}_{4}$ & $-0.1 \pm 0.6$ & $0.2 \pm 0.4$ & $0.4 \pm 1.0$ & $0.1 \pm 0.6$ & $0.1 \pm 0.5$ \\
\hline $\mathrm{EC}$ & $0.2 \pm 0.9$ & $0.6 \pm 0.7$ & $0.4 \pm 0.3$ & $0.2 \pm 0.9$ & $0.4 \pm 0.6$ \\
\hline $\mathrm{OC}$ & $0.2 \pm 0.8$ & $0.7 \pm 0.6$ & $0.3 \pm 0.4$ & $0.5 \pm 1.0$ & $0.8 \pm 0.6$ \\
\hline $\mathrm{Cl}$ & $0.4 \pm 0.7$ & $0.7 \pm 0.9$ & $0.3 \pm 0.3$ & $1.0 \pm 1.2$ & $0.7 \pm 0.7$ \\
\hline $\mathrm{Na}$ & $0.4 \pm 0.5$ & $0.6 \pm 0.5$ & $0.4 \pm 0.3$ & $0.8 \pm 0.6$ & $0.6 \pm 0.5$ \\
\hline total metals & $0.7 \pm 0.6$ & $0.9 \pm 0.5$ & $1.2 \pm 0.9$ & $1.2 \pm 0.8$ & $1.9 \pm 0.9$ \\
\hline not-analysed & $2.1 \pm 2.6$ & $1.6 \pm 2.5$ & $1.7 \pm 5.0$ & $2.9 \pm 1.6$ & $3.0 \pm 2.3$ \\
\hline
\end{tabular}
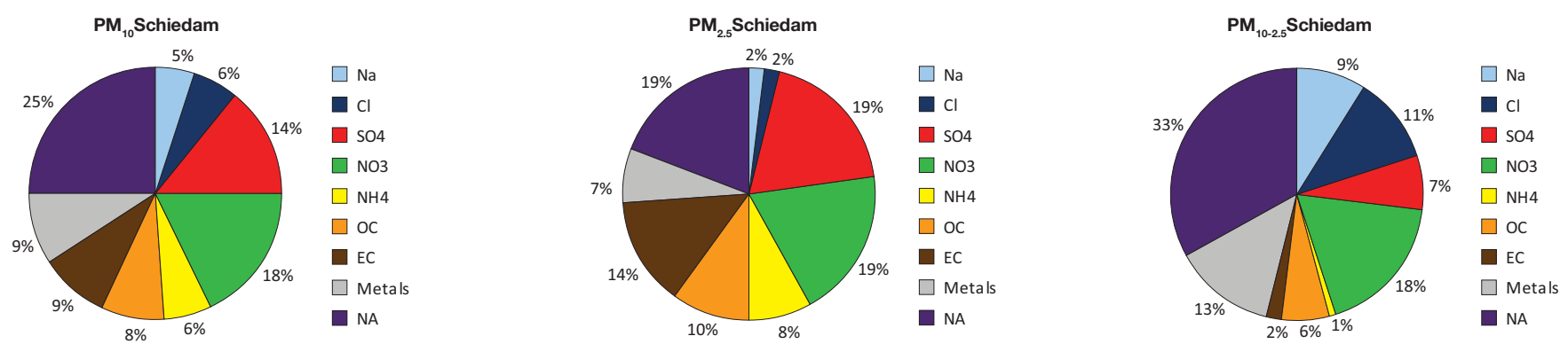

Fig. 3. Chemical distributions measured at the urban background site Schiedam.

than at Vredepeel which is a site known to be influenced by livestock activity. Although the rural location of Cabauw was less suspect in this respect, local emissions of ammonia cannot be excluded and it would explain the elevated concentrations. As a consequence, the assumption that Cabauw could serve as a background site for the urban region (containing the Rotterdam and Schiedam locations) is not confirmed. In addition, due to technical malfunctioning in the winter period 7 measurement days at Cabauw were missing. This explains the relatively low levels for sodium and chloride at this site. 
Table 3. Absolute and percentual change in mass concentrtion after applying conversion formula.

\begin{tabular}{|c|c|c|c|c|c|c|}
\hline & \multicolumn{2}{|c|}{$\mathrm{PM}_{10}$} & \multicolumn{2}{|c|}{$\mathrm{PM}_{2.5}$} & \multicolumn{2}{|c|}{$\mathrm{PM}_{10-2.5}$} \\
\hline & rural & urban & rural & urban & rural & urban \\
\hline \multicolumn{7}{|c|}{ associated oxygen } \\
\hline increase $\left(\mu \mathrm{g} \mathrm{m}^{-3}\right)$ & 0.9 & 1.2 & 0.3 & 0.4 & 0.5 & 0.8 \\
\hline$\%$-decrease of "NA" & $4 \%$ & $5 \%$ & $2 \%$ & $3 \%$ & $9 \%$ & $8 \%$ \\
\hline \multicolumn{7}{|c|}{ sea salt } \\
\hline increase $\left(\mu \mathrm{g} \mathrm{m}^{-3}\right)$ & 0.8 & 1.3 & 0.3 & 0.4 & 0.6 & 0.8 \\
\hline$\%$-decrease of "NA" & $4 \%$ & $5 \%$ & $2 \%$ & $3 \%$ & $10 \%$ & $9 \%$ \\
\hline \multicolumn{7}{|c|}{ nss sulphate } \\
\hline increase $\left(\mu \mathrm{g} \mathrm{m}^{-3}\right)$ & -0.2 & -0.3 & -0.1 & -0.1 & -0.1 & -0.2 \\
\hline$\%$-decrease of "NA" & $-1 \%$ & $-1 \%$ & $0 \%$ & $0 \%$ & $-2 \%$ & $-2 \%$ \\
\hline \multicolumn{7}{|c|}{ total carb. material } \\
\hline increase $\left(\mu \mathrm{g} \mathrm{m}^{-3}\right)$ & 1.1 & 1.5 & 0.9 & 1.2 & 0.3 & 0.3 \\
\hline$\%$-decrease of "NA" & $5 \%$ & $6 \%$ & $6 \%$ & $8 \%$ & $4 \%$ & $3 \%$ \\
\hline
\end{tabular}

The range of $\mathrm{OC}$ concentrations in $\mathrm{PM}_{10}$ lies between $1.6 \mu \mathrm{g} \mathrm{m}^{-3}$ (Hellendoorn, Cabauw) and $2.3 \mu \mathrm{g} \mathrm{m}^{-3}$ (Rotterdam). A recent study by Ten Brink et al. (2009) indicated that $70 \%$ of the OC in the Netherlands is contemporary (due to emissions from biogenic material and wood combustion). The remainder would originate from fossil-fuel sources (i.e. diesel traffic emissions). OC in the coarse fraction is highest at Vredepeel, Cabauw and Rotterdam (compared to Hellendoorn). At the first two sites this is probably related to nearby biogenic emissions nearby while at Rotterdam emissions are predominantly from vehicles.

\subsection{Conversion formula used in the mass closure approach}

Certain conversions were applied to the data set to identify the various constituents in PM. This procedure contained estimations of associated oxygen of metals, sea salt (SS), seasalt sulphate (SS-sulphate), total carbonaceous matter (TCM) and mineral dust (MD). The outcome effectively reduces the "not-analysed" part into a "not-explained" or "unknown" part in the final mass closure. We shortly discuss here the impacts on the mass closure (summarised in Table 3).

Elemental concentrations have been recalculated to their respective oxides to account for associated oxygen (Schaap et al., 2010). The summated "oxidised" contribution appeared 1.4 to 1.5 higher than the elemental contribution. Its incorporation had the largest effect on the coarse fraction: up to $1.0 \mu \mathrm{g} \mathrm{m}^{-3}$ (Rotterdam). The change in $\mathrm{PM}_{2.5}$ was rather small $\left(<0.4 \mu \mathrm{g} \mathrm{m}^{-3}\right)$. Consequently, the mass closure improved most for the coarse fraction (9\%, on average).

The sea-salt aerosol is generated by sea spray processes when waves break on the sea shore and out at sea. Here, sodium is used as a tracer because it is not affected by depletion and measurements are reliable. The presence of sea salt in the mass closure total is estimated by: $\mathrm{SS}=3.26 \cdot \mathrm{Na}$. The factor 3.26 follows from the composition of sea water (i.e., 11 sea water contains $1 \mathrm{~g}$ material among which $0.308 \mathrm{~g}$ sodium). The estimated SS contribution will differ from the actually measured sum of $\mathrm{Na}$ and $\mathrm{Cl}$ concentrations. The difference between this sum and the estimated SS contribution has to be discounted from the NA fraction. The measured $\mathrm{Na}$ and $\mathrm{Cl}$ concentrations are eliminated from the mass closure total after the SS constituent has been calculated. (The minor contributions of magnesium and other components present in seawater actually lead to a very small double counting as they are part of the "metals" fraction.) Generally, the application of the sea-salt conversion has a similar effect as the incorporation of oxidised elemental concentrations. Again the coarse fraction is affected most: the average sea-salt contribution rose with $0.7 \mu \mathrm{g} \mathrm{m}^{-3}$ which corresponded with an improvement of $10 \%$ in the mass closure. Double counting of sea-salt sulphate has been taken into account by subtraction of this contribution from the actually measured sulphate concentration. The sea salt contributions in relation to sulphate appear rather low $\left(<0.3 \mu \mathrm{g} \mathrm{m}^{-3}\right)$. The sea salt contribution to the coarse fraction and the effect of chloride depletion will be treated further in the Discussion.

Carbonaceous constituents contain elements other than carbon that contribute to the mass of PM (e.g., oxygen). The conversion from $\mathrm{OC}$ to organic material $(\mathrm{OM})$ is even quite uncertain in the US where many more monitoring data of OC/EC are available than in Europe. This is the reason to take a minimalistic approach for a conversion factor via the parameter TC. The use of total carbon in turn is due to the uncertain OC-EC split in the various chemical analysis approaches in use in Europe (Ten Brink et al., 2004). These analysis procedures correspond well for total carbon, but yield very different EC/OC ratios.

We follow here the approach of US-EPA (Frank, 2006) who compared total mass with summated contributions of the chemical components analysed for a very large number of filters. Frank obtained an optimal mass closure with total carbonaceous matter (TCM) defined as 1.3 times the amount of total carbon (TC). This is derived from measurements in the Speciation Trends Network which contains by definition urban background stations. Therefore, an average factor of 1.3 seems a good compromise in the present study with three types of stations (rural, urban background and kerbside). Using this approach the largest relative change is calculated for $\mathrm{PM}_{2.5}$ which is no surprise as TC is predominantly present in the fine fraction. The mass closure improved with some 7\% (for PM2.5). The maximum change was observed at the kerbside site in Rotterdam $\left(+1.4 \mu \mathrm{g} \mathrm{m}^{-3}\right.$ for $\left.\mathrm{PM}_{2.5}\right)$.

Mineral dust is defined here as fugitive wind-blown and mechanically resuspended soil dust with a composition comparable to the earth's crust containing elements like $\mathrm{Si}, \mathrm{Al}$, $\mathrm{Ca}, \mathrm{K}, \mathrm{Fe}$ and $\mathrm{Ti}$. In our data set the correlation between $\mathrm{Al}$ 

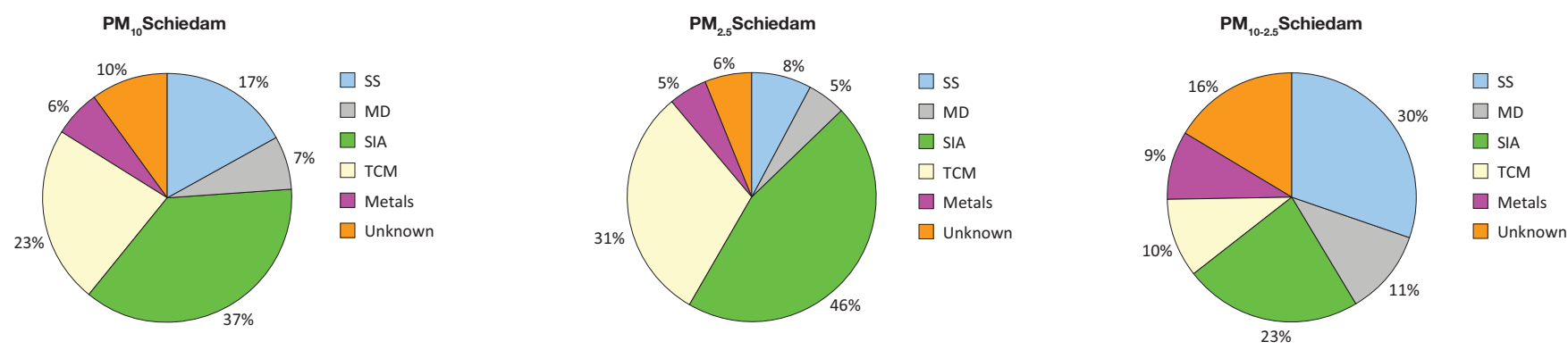

Fig. 4. Mass closures for the different fractions estimated at the urban background site Schiedam.

Table 4. Concentrations of the constituents as determined in the $\mathrm{PM}_{10}$ and $\mathrm{PM}_{2.5}$ data set for the five BOP-locations.

\begin{tabular}{|c|c|c|c|c|c|c|c|c|c|c|}
\hline \multirow[b]{2}{*}{ number of samples } & \multicolumn{2}{|c|}{ Hellendoorn } & \multicolumn{2}{|c|}{ Vredepeel } & \multicolumn{2}{|c|}{ Cabauw } & \multicolumn{2}{|c|}{ Schiedam } & \multicolumn{2}{|c|}{ Rotterdam } \\
\hline & $\begin{array}{c}38 \\
\text { conc } \pm \mathrm{sd}\end{array}$ & $\%$ & $\begin{array}{c}35 \\
\text { conc } \pm \text { sd }\end{array}$ & $\%$ & $\begin{array}{c}26 \\
\text { conc } \pm \text { sd }\end{array}$ & $\%$ & $\begin{array}{c}33 \\
\text { conc } \pm \text { sd }\end{array}$ & $\%$ & $\begin{array}{c}41 \\
\text { conc } \pm \text { sd }\end{array}$ & $\%$ \\
\hline $\mathrm{PM}_{10}$ & $17.7 \pm 6.4$ & & $21.2 \pm 7.3$ & & $23.6 \pm 11.9$ & & $21.8 \pm 9.6$ & & $26.3 \pm 11.6$ & \\
\hline SIA & $7.0 \pm 3.4$ & 40 & $8.0 \pm 4.2$ & 38 & $10.2 \pm 6.4$ & 43 & $8.0 \pm 6.6$ & 37 & $9.1 \pm 7.3$ & 35 \\
\hline TCM & $4.3 \pm 2.4$ & 28 & $5.0 \pm 2.0$ & 27 & $5.0 \pm 2.3$ & 24 & $4.9 \pm 2.5$ & 26 & $7.7 \pm 3.1$ & 32 \\
\hline SS & $2.0 \pm 2.0$ & 11 & $3.0 \pm 2.5$ & 14 & $1.6 \pm 1.2$ & 7 & $3.7 \pm 2.7$ & 17 & $2.9 \pm 2.1$ & 11 \\
\hline MD & $1.2 \pm 1.4$ & 7 & $1.2 \pm 1.0$ & 6 & $2.1 \pm 1.9$ & 9 & $1.6 \pm 1.3$ & 7 & $1.8 \pm 1.3$ & 7 \\
\hline metals & $0.8 \pm 0.3$ & 5 & $1.2 \pm 0.4$ & 6 & $1.0 \pm 0.4$ & 4 & $1.4 \pm 0.5$ & 6 & $2.4 \pm 0.8$ & 9 \\
\hline unknown & $2.3 \pm 3.5$ & 9 & $2.7 \pm 2.0$ & 10 & $3.7 \pm 4.2$ & 13 & $2.1 \pm 2.7$ & 7 & $2.3 \pm 2.8$ & 6 \\
\hline $\mathrm{PM}_{2.5}$ & $12.5 \pm 5.4$ & & $14.5 \pm 6.3$ & & $17.5 \pm 11.0$ & & $13.0 \pm 7.6$ & & $16.4 \pm 10.0$ & \\
\hline SIA & $6.0 \pm 2.8$ & 48 & $6.6 \pm 4.1$ & 46 & $8.4 \pm 6.1$ & 48 & $6.0 \pm 4.6$ & 46 & $6.8 \pm 5.1$ & 42 \\
\hline TCM & $3.8 \pm 1.9$ & 35 & $3.3 \pm 1.5$ & 28 & $3.9 \pm 2.0$ & 26 & $4.0 \pm 2.2$ & 36 & $6,1 \pm 2,7$ & 41 \\
\hline SS & $0.6 \pm 0.8$ & 5 & $1.0 \pm 0.9$ & 7 & $0.5 \pm 0.3$ & 3 & $1.0 \pm 0.8$ & 8 & $0.9 \pm 1.0$ & 5 \\
\hline MD & $0.5 \pm 0.4$ & 4 & $0.5 \pm 0.3$ & 3 & $0.7 \pm 0.4$ & 4 & $0.6 \pm 0.5$ & 5 & $0.6 \pm 0.3$ & 4 \\
\hline metals & $0.4 \pm 0.2$ & 4 & $0.6 \pm 0.1$ & 4 & $0.5 \pm 0.2$ & 3 & $0.6 \pm 0.2$ & 5 & $0.8 \pm 0.3$ & 5 \\
\hline unknown & $1.2 \pm 1.7$ & 5 & $2.5 \pm 2.6$ & 13 & $3.5 \pm 5.5$ & 16 & $0.7 \pm 2.2$ & 1 & $1.2 \pm 3.5$ & 3 \\
\hline $\mathrm{PM}_{10-2.5}$ & $5.1 \pm 2.1$ & & $6.8 \pm 2.9$ & & $6.1 \pm 2.5$ & & $8.8 \pm 3.6$ & & $9.9 \pm 3.4$ & \\
\hline SIA & $1.0 \pm 1.5$ & 14 & $1.4 \pm 1.6$ & 21 & $1.8 \pm 4.5$ & 29 & $2.0 \pm 2.8$ & 23 & $2.3 \pm 2.9$ & 23 \\
\hline TCM & $0.5 \pm 2.0$ & 9 & $1.7 \pm 1.4$ & 25 & $1.1 \pm 0.9$ & 18 & $0.9 \pm 0.9$ & 10 & $1.6 \pm 1.1$ & 16 \\
\hline SS & $1.4 \pm 1.5$ & 28 & $2.0 \pm 1.7$ & 30 & $1.2 \pm 0.9$ & 19 & $2.7 \pm 2.0$ & 30 & $2.0 \pm 1.5$ & 21 \\
\hline MD & $0.7 \pm 1.0$ & 14 & $0.8 \pm 0.7$ & 11 & $1.4 \pm 1.5$ & 23 & $1.0 \pm 1.2$ & 11 & $1.2 \pm 1.0$ & 12 \\
\hline metals & $0.4 \pm 0.2$ & 8 & $0.6 \pm 0.3$ & 9 & $0.5 \pm 0.3$ & 8 & $0.8 \pm 0.4$ & 9 & $1.6 \pm 0.7$ & 16 \\
\hline unknown & $1.1 \pm 3.0$ & 21 & $0.2 \pm 2.2$ & 4 & $0.2 \pm 5.0$ & 3 & $1.4 \pm 2.0$ & 16 & $1.1 \pm 2.3$ & 12 \\
\hline
\end{tabular}

and Si turned out to be very good $\left(r^{2}=0.96\right)$. This suggests that both originate from the same source and are present in similar ratios. The method to estimate the contribution of MD here is by focusing on these two abundant elements according to $\mathrm{MD}=0.49 \cdot \mathrm{Si}+(2.36 \cdot \mathrm{Si}+2.7 \cdot \mathrm{Al})$ (proposed by Denier van der Gon, 2009). All elemental weights were recalculated first to their respective oxide concentrations. The calculated MD contribution is subtracted from the total elemental mass which leaves the final mass balance unaffected. The result is further denoted by "metals".

\subsection{Mass closure}

The resulting concentrations of the various constituents are given in Table 4. The resulting mass closure is again given for the Schiedam site in Fig. 4. The dominant constituent in the $\mathrm{PM}_{2.5}$ filter samples is the secondary inorganic components (SIA). There is not much difference between most measurement sites as concentrations range between 6 and $7 \mu \mathrm{g} \mathrm{m}^{-3}$. A maximum occurs at Cabauw $\left(8.4 \mu \mathrm{g} \mathrm{m}^{-3}\right)$ due the enhanced levels of ammonium and nitrate noted earlier. The second important contribution comes from total carbonaceous matter (TCM) showing more variation. TCM in 
$\mathrm{PM}_{2.5}$ is higher at the urban sites $\left(4.0-6.1 \mu \mathrm{g} \mathrm{m}^{-3}\right)$ than at the rural sites (3.3-3.9 $\mathrm{\mu g} \mathrm{m}^{-3}$ ). The remaining constituents, i.e., sea salt (SS), mineral dust (MD), and metals contribute considerably less with concentrations always below $1 \mu \mathrm{g} \mathrm{m}^{-3}$. The unexplained part in the $\mathrm{PM}_{2.5}$ mass fraction tends to be higher at the rural sites with a maximum at Cabauw of $3.5 \mu \mathrm{g} \mathrm{m}^{-3}$. At the other sites the missing part was always less than $2.5 \mu \mathrm{g} \mathrm{m}^{-3}$.

The presence of the various constituents in the coarse fraction is more evenly distributed than in the fine fraction. Relatively high contributions arise from sea salt $\left(\leq 2.7 \mu \mathrm{g} \mathrm{m}^{-3}\right.$; maximum at Schiedam) and SIA $\left(\leq 2.3 \mu \mathrm{g} \mathrm{m}^{-3}\right.$; higher levels at Rotterdam and Schiedam). The concentrations of $\mathrm{MD}$ and the remaining metals are always less than $1.4 \mu \mathrm{g} \mathrm{m}^{-3}$ (Cabauw) and $1.6 \mu \mathrm{g} \mathrm{m}^{-3}$ (Rotterdam), respectively. Remarkable is the rather high TC levels at Vredepeel $\left(1.3 \mu \mathrm{g} \mathrm{m}^{-3}\right)$ and Cabauw $\left(0.7 \mu \mathrm{g} \mathrm{m}^{-3}\right)$ compared to Rotterdam $\left(1.2 \mu \mathrm{g} \mathrm{m}^{-3}\right)$ and Schiedam $\left(0.7 \mu \mathrm{g} \mathrm{m}^{-3}\right)$. The reason for these enhanced TC levels in the coarse fraction is not clear.

To determine which of the constituents are the main contributors when high PM levels (e.g., on exceedence days) occur the data set has been partitioned into two subsets, containing the data for days at which the $\mathrm{PM}_{10}\left(\mathrm{PM}_{2.5}\right)$ concentrations were less or larger than $30(25) \mu \mathrm{g} \mathrm{m}^{-3}$. Not surprisingly, the absolute contributions of most constituents rise when PM increases. The difference between the $\mathrm{PM}_{10}$ levels when averaged over the two sets is $20 \mu \mathrm{g} \mathrm{m}^{-3}$. The largest changes in absolute concentrations are observed for SIA $\left(+11 \mu \mathrm{g} \mathrm{m}^{-3}\right.$ in $\left.\mathrm{PM}_{10}\right)$ and the unknown part $\left(+6 \mu \mathrm{g} \mathrm{m}^{-3}\right)$ followed by smaller or negligible changes for TCM $\left(+3 \mu \mathrm{g} \mathrm{m}^{-3}\right)$, MD $\left(+1.5 \mu \mathrm{g} \mathrm{m}^{-3}\right)$ and metals $\left(<+0.5 \mu \mathrm{g} \mathrm{m}^{-3}\right)$. The only exception is sea salt which decreases at higher PM levels $\left(-1.8 \mu \mathrm{g} \mathrm{m}^{-3}\right)$. The corresponding changes in chemical distributions of $\mathrm{PM}_{10}$ and $\mathrm{PM}_{2.5}$ are summarised in Fig. 5. It can be seen that when expressed in percentages both SIA and the unknown part become more dominant at days with more PM. Correspondingly, the relative contributions of the remaining constituents (MD, TCM and SS) decrease at higher PM concentrations.

The two measurement sites in the Rotterdam urban area allow investigating which components are emitted by traffic by comparing measured concentrations at the kerb site (Rotterdam) to those at the urban background site (Schiedam). The difference in $\mathrm{PM}_{10}$ between the two sites appeared $3.5 \mu \mathrm{g} \mathrm{m}^{-3}$ (based on 27 corresponding days) and can be attributed to carbonaceous material $\left(2.5 \mu \mathrm{g} \mathrm{m}^{-3}\right)$ and metals $\left(1 \mu \mathrm{g} \mathrm{m}^{-3}\right)$. The carbonaceous material increment is largely due to elementary carbon. The metals that are enhanced include copper, iron, barium and molybdenum and result from tail-pipe emissions, and brake and tire wear. Surprisingly, there is no similar increment in the concentrations of mineral dust implying that this is not an important source at Rotterdam. As this disagrees with the outcomes described in other Dutch studies (e.g., Visser et al., 2001) and elsewhere

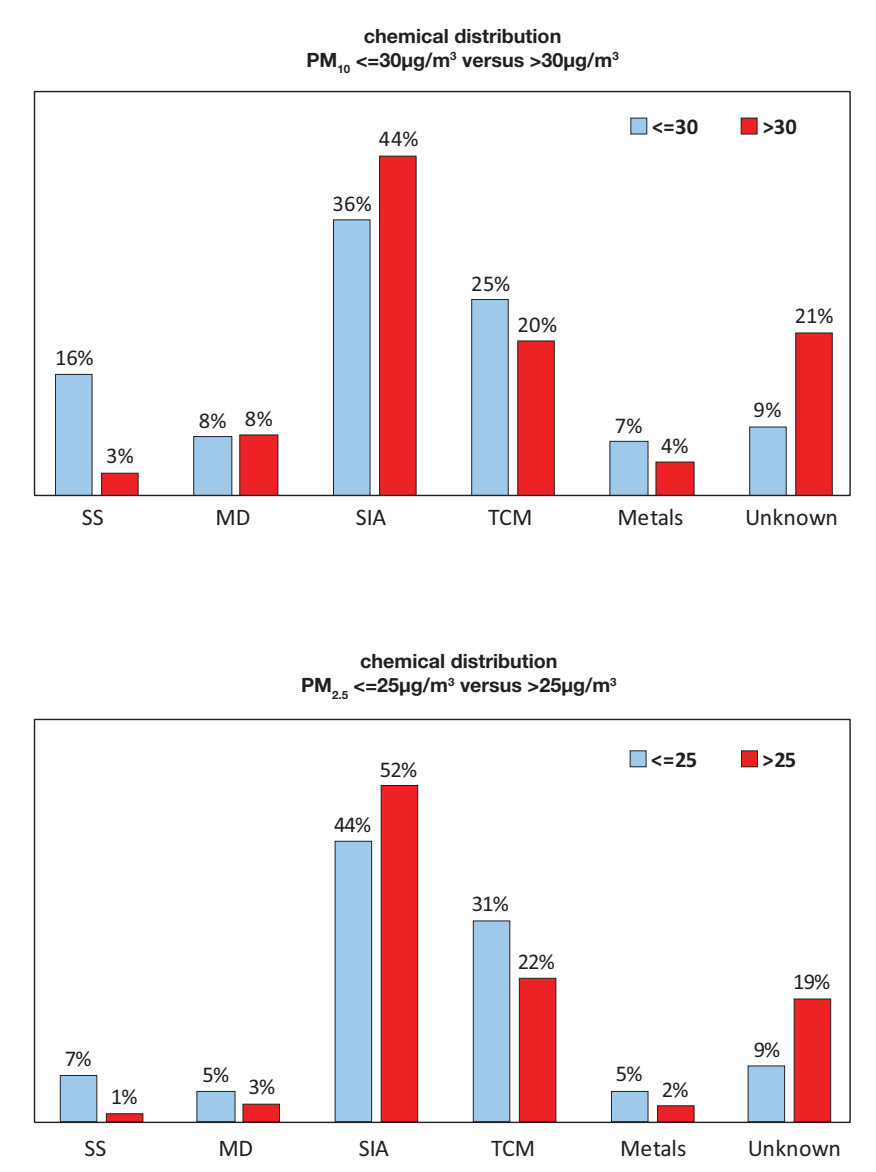

Fig. 5. Average chemical distributions in data subsets with high and low PM concentrations. Above: $\mathrm{PM}_{10}>30 \mu \mathrm{g} \mathrm{m}^{-3}$ vs. $\mathrm{PM} \leq 30 \mu \mathrm{g} \mathrm{m}^{-3}$; below $\mathrm{PM}_{2.5} \leq 25 \mu \mathrm{g} \mathrm{m}^{-3}$ vs. $\mathrm{PM}_{2.5}>25 \mu \mathrm{g}$ $\mathrm{m}^{-3}$. Averages over the five BOP stations.

(e.g., Amato et al., 2009) further investigation on the origin of mineral dust and the role of traffic at the Rotterdam site is necessary.

\section{Discussion}

\subsection{Chemical composition}

The data set gives a proper insight in the chemical characteristics of PM in the Netherlands. Generally, a considerable similarity in the chemical composition of PM is observed at the five measurement sites. Always, secondary inorganic components are the dominant constituent with contributions responsible for nearly half of the total mass $(42-48 \%$ of $\mathrm{PM}_{2.5}$ ) with nitrate being the most important component. The variation in SIA concentrations appears rather limited indicating that its behaviour is mainly driven by larger-scale meteorology and not by local sources (Weijers et al., 2010). Nearby emissions of ammonia may incidentally lead to locally high levels (e.g., Cabauw). The next important contribution originates from total carbonaceous matter showing 
more variation over the sites studied here (22-37\%). TCM in $\mathrm{PM}_{2.5}$ tends to be higher in areas where more traffic prevails (Rotterdam, Schiedam). The remaining constituents, i.e., sea salt, mineral dust and metals are relatively unimportant as they contribute each less than $8 \%$.

This study allows the first detailed overview of the chemical composition of the coarse fraction in the Netherlands. Compared to the fine fraction both SIA and TCM are less dominant (around 29\% and 25\%, respectively) becoming comparable with mineral dust $(<23 \%)$ and sea salt $(<30 \%)$. The remaining metals sum up to $16 \%$ (Rotterdam). It was further noted that at the two urban sites considerable part of SIA $(25 \%)$ was in the coarse fraction. It is assumed that in the marine urban environment (Schiedam and Rotterdam are within $30 \mathrm{~km}$ of the seashore) the coarse sea-salt particles act as reactive sinks for nitric and sulphuric acids. The implications of these mechanisms will be discussed further below.

As anticipated, absolute contributions of most constituents rise when PM concentrations go up. However, this does not occur at the same rate for each constituent. The largest increase is observed for SIA, most notably nitrate, and the missing mass part. By consequence, the chemical distribution rearranges at days with higher PM concentrations: SIA and the unknown part become more dominant, the contribution of mineral dust remains the same while the relative importance of TCM and sea salt decrease. Such behaviour can be explained by considering the atmospheric situation these days and the localisation of the major emissions. The high concentrations of $\mathrm{PM}_{2.5}$ and $\mathrm{PM}_{10}$ occur at days with stagnating conditions or slow transport from south, south-east or east. As the emissions are diluted less due to the lower wind speeds and removal is low, pollution starts to build up. During the winter period this effect is strengthened due to the shallow boundary layers. In view of the dominant transport direction (continental) it is not surprising that the contribution of sea salt diminishes. In addition to unfavourable meteorological conditions, considerable emissions for $\mathrm{SO}_{2}$ and $\mathrm{NO}_{\mathrm{x}}$ take place east of the Netherlands (industrial Ruhr area); for $\mathrm{NH}_{3}$ this is in the Southeast (a centre of intensive livestock industry). Model studies also indicate high contributions of national sources to the concentrations of primary material and ammonium nitrate (Schaap and Denier van der Gon, 2007). Also some special events contribute to a (small) number of exceedences or days with high concentrations. In the data set we have identified contributions from desert dust, fireworks at New Year's Eve, and bonfires at Easter.

\subsection{Mass closure and the unknown part}

To correct for known underestimations a number of algorithms to estimate various constituents has been applied. Most of these (oxide concentrations, sea salt, total carbon material) improve the mass closure. In the case of $\mathrm{PM}_{2.5}$ the conversion from TC to TCM results in a more complete mass closure in the $\mathrm{PM}_{2.5}$ samples at the urban sites (93-94\%).
The closure appears less perfect at the rural sites $(80,83$ and $90 \%$ ) demonstrating the sensitivity on site characteristics. In contrast to the fine fraction, the mass closure in the coarse fraction seems better at the rural sites. The unexplained parts are now less than $4 \%$ of the total mass (which is in absolute mass units negligible) while in the urban environment this is 12 (Rotterdam) and $16 \%$ (Schiedam) or, 1 and $1.5 \mu \mathrm{g} \mathrm{m}^{-3}$, respectively.

A similarity has been noted between SIA in $\mathrm{PM}_{2.5}$ (more specific, nitrate and, to a lesser extent, ammonium) and the unexplained mass. The largest mass deficit (measured at Cabauw) coincides with the highest SIA concentration; at Schiedam minimum SIA concentrations and mass deficit have been measured. To a lesser extent, similar behaviour is seen in the coarse mass fraction. Here, SIA concentrations at the urban sites are (somewhat) higher and correspond with larger mass deficits. By consequence, the "contribution" of the unexplained mass is also important at days with higher PM concentrations since the presence of SIA (or more specific nitrate) is the main reason for these augmented levels.

A possible reason may be the amount of water attached to SIA. Hygroscopic salts on particles, like ammonium nitrate and ammonium sulphate in the fine fraction, and sodium nitrate and sodium sulphate in the coarse fraction attract water erroneously increasing the PM mass measurements. It is estimated that the amount of water on $\mathrm{PM}_{10}$ due to the presence of SIA is about $10 \%$ of the SIA mass which is $4-5 \%$ of the $\mathrm{PM}_{10}$ mass concentration. Such a contribution is possible as it is lower than the total unexplained mass but also implies that it can not be the sole contributor to the unexplained mass.

\subsection{Role of nitrate}

According to the formation pathways ammonia gas reacts reversibly with $\mathrm{HNO}_{3}$ to form its ammonium salt, $\mathrm{NH}_{4} \mathrm{NO}_{3}$, which is semi-volatile and may release their gas phase precursors under conditions of low atmospheric $\mathrm{NH}_{3}$ levels or high temperature according to $\mathrm{NH}_{3}+\mathrm{HNO}_{3} \leftrightarrow \mathrm{NH}_{4} \mathrm{NO}_{3}$. In marine and coastal atmospheres, nitric acid is also converted into particulate nitrate $\left(\mathrm{NaNO}_{3}\right)$ through the reaction with sea salt particles resulting in the release of $\mathrm{HCl}$ : $\mathrm{NaCl}+\mathrm{HNO} 3 \rightarrow \mathrm{NaNO}_{3}+\mathrm{HCl}$. In contrast to $\mathrm{NH}_{4} \mathrm{NO}_{3}$, $\mathrm{NaNO}_{3}$ is a non-volatile compound under atmospheric conditions therefore, partitioning of nitric acid into the sea salt is irreversible. In the Netherlands most of the nitrate is found in the fine mode as ammonium nitrate. However, the coarse nitrate fraction is still a substantial part of the analysed coarse mode (Table 2). The coarse-to- $\mathrm{PM}_{10}$ ratio in the case of nitrate appears near $40 \%$ at the urban sites (and some $26 \%$ at the rural sites).

From this formation pathway the problem arises how to correctly assign the coarse mode nitrate to the PM constituents SIA and SS, respectively. In the chemical mass balance sodium is used as a tracer of sea salt multiplying 
its concentration with a factor to obtain an estimate of fresh sea-salt aerosol, including all the chloride. Hence, when one would put both the sea salt estimate and the full coarse mode nitrate into the SS constituent, the sea salt and nitrate contributions cannot simply be added as the nitrate replaces chloride. Consequently, one needs to make a correction in the chemical mass balance approach for this double counting.

In principle, there are two options here. The first is to replace (on a molar basis) a part or all of the estimated chloride concentration in the SS constituent by the measured coarse nitrate concentration. In the case that the coarse nitrate exceeds the estimated chloride the remaining part of nitrate is kept in the SIA constituent. The second option is to keep the estimated SS constituent as it is and to discount from the SIA constituent the coarse nitrate fraction that potentially may replace the sea salt chloride. The first option reflects the substitution processes taking place on sea salt particles. The second option reflects the sources and especially the associated reduction potential. Though both choices are valid and defendable, it can be argued that the second option suits better if we are after the source apportionment. Reduction of $\mathrm{NO}_{\mathrm{x}}$ emissions may cause a reduction of coarse mode nitrate, which is partly compensated by the fact that chloride is not lost anymore. Such a reduction would yield a net result of $\left(\left(\mathrm{NO}_{3}-\mathrm{Cl}\right) / \mathrm{NO}_{3}=(62-35) / 62=\right) 27 / 62$ times the nitrate reduction (where the number involved are molar weights of the respective components). Hence, this factor could be used to scale back the coarse nitrate fraction in the chemical mass balance. The motivation would be that when all anthropogenic sources would be non-existing one still has the sea salt left that is given now in the mass distributions. Doing so, the coarse nitrate would, on average, be lower with some $0.6 \mu \mathrm{g} \mathrm{m}^{-3}$ which gives an increase in the NA part of the coarse fraction with some $4 \%$. A similar reasoning may be valid for the anthropogenic sulphate in the coarse fraction. Corrections like these are uncommon in current mass closure studies and consequences will have to be explored in more detail in future.

\subsection{Natural fraction}

For policy makers the extent to which particulate matter can be influenced by measures is of importance. It is the anthropogenic part that could be targeted by abatement strategies. Here, a first-order approximation of the natural and anthropogenic contribution to $\mathrm{PM}_{10}$ and $\mathrm{PM}_{2.5}$ is developed.

Sea spray emissions are the most important natural source of primary sulphate. Applying the sodium-to-sulphate ratio learns that roughly $5 \%$ of the particulate sulphate is marine. Though sulphate may be emitted directly into the atmosphere, its major source is the oxidation of sulfur dioxide. In the Netherlands anthropogenic $\mathrm{SO}_{2}$ emissions derive mostly from the combustion of sulfur containing fuels for power generation and international shipping. In Europe, natural emissions for $\mathrm{SO}_{2}$ include volcanoes but given loca- tion, height and distance to the Netherlands their contribution is probably low (i.e., not more than 1 percent to ground level sulphate). Contributions of other biogenic sources of $\mathrm{SO}_{2}$ like oxidation of DMS, $\mathrm{COS}$ and $\mathrm{H}_{2} \mathrm{~S}$ are also of minor importance (Bates et al., 1992). Wildfire emissions of $\mathrm{SO}_{2}$ are commonly neglected in studies directed to wild land fire emissions. In the approximation here 5\% is used as a conservative estimate.

To estimate how much of the nitrate is natural $\mathrm{NO}_{\mathrm{x}}$ emissions from soil, biomass burning and lightning should be considered. Studies on NO emissions from soil report emissions between 59 and 190 Kton in the EU15 (Simpson et al., 1999; Friedrich et al., 2008). Relative to the total inventoried emissions the central value is $4 \%$. From these emissions about two third is attributed to agricultural soils and one third to forest soils. Soil $\mathrm{NO}_{\mathrm{x}}$ emissions largely depend on the nutrient input (through fertilization or atmospheric deposition) implying that the abovementioned contribution is only partly natural. Lightning depends linearly on the amount of convective precipitation. In Europe corresponding emissions are estimated to be about $1 \%$ ( $65 \mathrm{Kton}$ ) of the total inventoried emissions It mainly takes place between 1 and $5 \mathrm{~km}$ altitude and mostly in southern Europe (Meijer et al., 2001; Friedrich et al., 2008). The available wild fires estimates range between 20-50 Kt (Friedrich et al., 2009; Hoelzemann et al., 2004) and also occur mostly in countries around the Mediterranean. Given the short life time of $\mathrm{NO}_{\mathrm{x}}$ and the rather short transport distance of nitrate we assume the impact of lightning and wild land fires can be negligible $(<1 \%)$ in the Netherlands. In the approximation the natural fraction of $\mathrm{NO}_{\mathrm{x}}$ emissions and therewith nitrate is taken between 0 and $5 \%$.

Ammonia is emitted from, most notably, animal manure, traffic and fertilizer application (Olivier et al., 1998). Emissions in Europe are for the largest part (80-95\%) associated with agricultural activities (van der Hoek, 1998). Recently, Erisman et al. (2009) estimated the natural emissions at about $10 \%$ of the total emission in Europe. This percentage includes contributions from wild animals and wetlands. A similar percentage is assumed for the Netherlands.

Elemental carbon is emitted from combustion processes and a pure primary component. The main source is the (incomplete) combustion of fossil fuels. Wild land fires are occasional sources of vast amounts of carbonaceous particles. Though wild land fires may seem natural, the vast majority of present day fires are due to human behavior. Hence, elemental carbon is almost exclusively anthropogenic.

Organic matter is released from combustion processes, agricultural activities as well as from nature. Anthropogenic combustion particles (as well as small contribution of stable emissions) are inventoried. About half of the observed concentrations of OC (Schaap et al., 2004; Simpson et al., 2007) can be explained. Other primary sources include biological material (fungal spores and plant debris) contribute up to $0.4 \mu \mathrm{g} \mathrm{m}^{-3}$ (about $6 \%$ of OM) at rural background sites in 
Table 5. Illustration of natural contribution (in \%) for all components in the case of Hellendoorn. For each component the relative contribution to $\mathrm{PM}_{2.5}$ and $\mathrm{PM}_{10}$ is listed as well as the estimated natural contribution. The two columns on the right provide the resulting natural contribution to $\mathrm{PM}_{10}$ and $\mathrm{PM}_{2.5}$ for each component for a high and low estimate of the natural OC content. All numbers are percentages.

\begin{tabular}{lrrrrr}
\hline Comp & $\begin{array}{r}\mathrm{PM}_{10} \\
\text { Contrib. }\end{array}$ & $\begin{array}{r}\mathrm{PM}_{2.5} \\
\text { Contrib. }\end{array}$ & $\begin{array}{r}\text { Natural } \\
\text { Low/high }\end{array}$ & $\begin{array}{r}\text { Hellendoorn } \\
\mathrm{PM}_{10} \\
\text { Low/high }\end{array}$ & $\begin{array}{r}\text { Hellendoorn } \\
\mathrm{PM}_{2.5} \\
\text { Low/high }\end{array}$ \\
\hline $\mathrm{NO}_{3}$ & 21 & 21 & $0-5$ & $0-1$ & $0-1$ \\
$\mathrm{SO}_{4}$ & 13 & 17 & 5 & 1 & 1 \\
$\mathrm{NH}_{4}$ & 7 & 10 & 10 & 0.5 & 1 \\
$\mathrm{MD}$ & 7 & 4 & 10 & 1 & 0.5 \\
$\mathrm{SS}$ & 11.5 & 5 & 100 & 11.5 & 5 \\
Metals & 5 & 4 & 0 & 0 & 0 \\
EC 1.3 & 12 & 15 & 0 & 0 & 0 \\
OC 1.3 & 12 & 14 & $25 / 50$ & $3 / 6$ & $3.5 / 7$ \\
Sum known & & & & $16.5 / 21$ & $11 / 15.5$ \\
Unknown & 13 & 10 & $*$ & $2.5 / 3$ & $1.5 / 1.5$ \\
Total & & & & $19 / 24$ & $13 / 17$ \\
\hline
\end{tabular}

* Natural contribution is assumed to be the same as the total natural percentage of the explained mass.

central Europe (Sanchez-Ochoa et al., 2008). Recently, ${ }^{14} \mathrm{C}$ analysis suggested that some $70 \%$ (Ten Brink et al., 2010) of the OC mass in the Netherlands was of living material where biogenic SOA, agriculture and other landscaping activities may have contributed. The complicating factor in the estimation of the natural part of OM is the uncertainty related to its secondary component (oxidation of VOCs yields products with low vapor pressures that may condense on existing aerosol) as the major formation routes are not well known. Similarly, the ratio of natural to anthropogenic SOA is under large scientific debate. Note that the oxidation pathways that yield SOA are largely influenced through hydroxyl and ozone from anthropogenic emissions. Presently, it is postulated that biogenic sources are a major contributor to atmospheric SOA (e.g. Simpson et al., 2007). Assuming that the unexplained OC using present day emission inventories is for the largest part SOA an upper limit of $\sim 50 \%$ of natural OM is obtained. As a substantial part of the SOA may very well be anthropogenic we postulate a second guess with half of the SOA as natural, leading to a lower limit of $25 \%$ of natural OM.

Mineral dust usually originates from different sources, e.g., wind erosion of bare soils, agricultural land management, re-suspension of road dust, road wear, driving on unpaved roads, handling of materials and building and construction activities. The contributions of these sources are still poorly understood. Here, only wind erosion is relevant as natural source. Globally the atmospheric input through wind erosion is dominated by a few areas exceptionally susceptible for wind erosion. Saharan dust is regularly transported to countries around the Mediterranean Sea. In central and northern Europe dust transport from the Sahara occurs once or twice a year and is not considered very significant. During this study we could only identify one day with a significant impact of Saharan dust to PM (contribution $~ 4 \%$ of the annual mean MD concentration). Korcz et al. (2009) and Schaap et al. (2009) show that wind blown dust at the European continent is a much smaller source for dust than traffic re-suspension and agricultural land management. More importantly, the wind blown dust source strength from soils other than arable land is low. Hence, wind blown dust emissions are strongly related to anthropogenic changes in surface vegetation cover and are regarded as mostly anthropogenic. Consequently, the total mineral dust concentration in air is expected to be anthropogenic for a large part. In the approximation $10 \%$ is assumed as a conservative estimate for the natural contribution to MD.

Metals originate from a vast range of abrasion processes and metallurgy industry. Though soils may contribute to metal concentrations they are in principle accounted for in the mineral dust estimate. Here, all metals are assumed to be anthropogenic.

The natural fraction of the unknown mass is by definition unknown. As water partly explains the unknown fraction and most of the water appears associated with SIA it is likely that a significant part of the unknown fraction can be considered to anthropogenic. We assume here that the anthropogenic/natural ratio within the unknown mass fraction resembles that of the explained mass.

The natural fraction in the Netherlands is then obtained by adding relative natural mass contributions per component. For instance, in Hellendoorn $11.5 \%$ of $\mathrm{PM}_{10}$ is associated with sea salt adding to $11.5 \%$ of natural $\mathrm{PM}_{10}$ (see Table 5). Note, that this fraction represents the source attribution and therewith fresh sea salt as discussed in Sect. 4.3 and would be lower when one reflects the chloride loss in this calculation. Nitrate contributes $21 \%$ of which $0-5 \%$ is assumed to be natural resulting in a contribution of $0-1 \%$ natural $\mathrm{PM}_{10}$ for the low and high cases, respectively. Hence, nitrate contributes very little to the natural fraction. Adding all contributions, the estimated natural fraction of $\mathrm{PM}_{10}$ is $24 \%$. With the lower estimate for carbonaceous particles yields a natural fraction of $19 \%$. Hence, around one quarter of $\mathrm{PM}_{10}$ is estimated to be natural. Performing the same exercise for $\mathrm{PM}_{2.5}$ yields estimates of 17 and $13 \%$ for the two cases, respectively. Application of this methodology to all sites in this campaign yields natural fractions of about one fourth for $\mathrm{PM}_{10}$ and one fifth for $\mathrm{PM}_{2.5}$ (Fig. 6). In case of the low natural OM fraction the natural estimates are about 5\% lower than with the high case.

\section{Conclusions}

There is a considerable conformity in the chemical composition of PM over the Netherlands. Most dominant is the secondary inorganic aerosol - the sum of sulphate, nitrate 


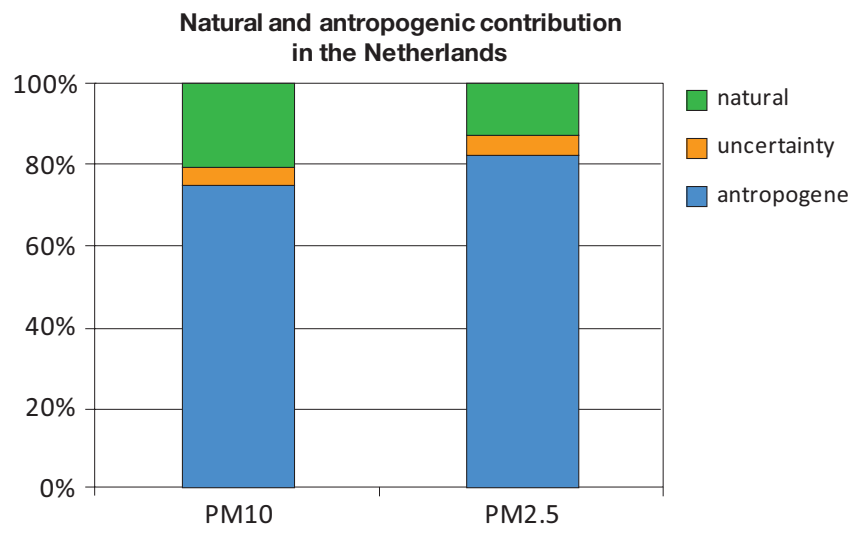

Fig. 6. Natural and anthropogenic contributions to $\mathrm{PM}_{10}$ and $\mathrm{PM}_{2.5}$ as estimated from the BOP data set.

and ammonium - showing slightly higher levels at the rural sites. Carbon containing components are generally the second largest contributor being enhanced in the traffic dominated urban area. The most important natural constituent is sea salt, especially in the western part of the Netherlands near the North Sea. Contributions of mineral dust and metals appear relatively low. The distribution of species in $\mathrm{PM}_{10}$ resembles that of $\mathrm{PM}_{2.5}$ which is not surprising as the mass of $\mathrm{PM}_{2.5}$ is about two thirds of the total $\mathrm{PM}_{10}$ mass. The chemical composition observed in the coarse mass fraction appears more balanced: contributions of mineral dust and sea salt are of comparable magnitude with those of SIA and TCM.

On days with high PM concentrations, all constituents, except sea salt, show higher concentrations. Sea salt maximises in marine air masses associated with clean air conditions. The nitrate and unknown contributions increase most on these days suggesting a relationship by means of the associated water content. The relative contribution of the remaining components is mostly stable as function of PM concentration.

After analysing the filter samples on chemical content the sum of all the components accounts on average for $70-80 \%$ of the total mass. Hence, a full analysis is not obtained, but existing knowledge can be used to narrow down partially the remaining gap. For example, metals can be taken into account as their oxides and total carbonaceous matter (including non-C atoms) is estimated based on the total carbon content. In addition, the contributions of mineral dust and sea salt were estimated. After this procedure, 80 to $94 \%$ of the total mass can be explained. Uncertainties occurring in the mass closure are conversion factors for total carbonaceous matter and the displacement of chloride by nitrate in the coarse fraction.

Based on a literature review, it is concluded that the most important natural contributions originate from sea salt (100\%) and organic material (with an upper limit of 50\%). Including the natural parts of the remaining constituents, es- timates for the entire natural contribution yield $19-24 \%$ for $\mathrm{PM}_{10}$ and $13-17 \%$ for $\mathrm{PM}_{2.5}$. This (fairly pragmatic) analysis illustrates that the majority of PM in the Netherlands is of anthropogenic origin.

A major gap in knowledge remains the characterisation of the unknown mass and the role of the water content of the filter. Another caveat is the chemical characterisation of the urban increment (with respect to rural background concentrations). The technical inability in the differentiation between EC and OC influences results. For more traditional PM components, like SIA and primary material, a modelling may identify source contributions at sector level, and provide insight into national versus foreign sources. The origin of carbonaceous matter remains one of the biggest challenges, as knowledge in this respect is still moderate.

Acknowledgements. This study is conducted under the auspices of the Netherlands Research Program on Particulate Matter (BOP), a national program on $\mathrm{PM}_{10}$ and $\mathrm{PM}_{2.5}$, funded by the Netherlands Ministry of Housing, Spatial planning and the Environment (VROM). The program is a framework of cooperation, involving four Dutch institutes: the Energy research Centre of the Netherlands (ECN), the Netherlands Environmental Assessment Agency (PBL), the National Institute for Public Health and the Environment (RIVM), and TNO Built Environment and Geosciences.

Edited by: H. Saathoff

\section{References}

Amato, F., Pandolfi, M., Escrig, A., Querol, X., Alastuey, A., Pey, J., Perez, N., and Hopke, P. K.: Quantifying road dust resuspension in urban environment by multilinear engine: A comparison with PMF2, Atmos. Environ., 43, 2770-2780, 2009.

Almeida, S. M., Pio, C. A., Freitas, M. C., Reis, M. A., and Trancoso, M. A.: Source apportionment of fine and coarse particulate matter in a sub-urban area at the Western European Coast, Atmos. Environ. 39, 3127-3138, 2005.

Bates, T. S., Lamb, B. K., Guenther, A., Dignon, J. and Stoiber, R. E.: Sulfur emissions to the atmosphere from natural sources, J. Atmos. Chem., 14, 315-337, 1992.

Brunekreef, B. and Holgate, S. T.: Air Pollution and Health, Lancet, 360, 1233-1244, 2002.

Denier van der Gon, H., Jozwicka, M., Hendriks, E., Gondwe, M. and Schaap, M.: Mineral dust as a constituent of particulate matter, PBL report 500099003, Bilthoven, the Netherlands, 2010.

Dockery, D., Pope, C. A., Xu, X., Spengler, J., Ware, J., Fay, M., Ferris, B., and Speizer, F.: An association between air pollution and mortality in six US cities, New Engl. J. Med. 329,17531759, 1993.

EU: Directive 2008/50/EC of the European Parliament and of the Council on ambient air quality and cleaner air for Europe, 2008.

EEA: Air pollution in Europe 1990-2004, EEA report 2/2007, Copenhagen, 2007.

Erisman, J. W., Sutton, M. A., Galloway, J., Klimont, Z., and Winiwarter, W.: How a century of ammonia synthesis changed the world, Nat. Geosci., 1, 636-639, 2009. 
Frank, N. H.: Retained nitrate, hydrated sulfates, and carbonaceous mass in Federal Reference Method fine particulate matter for six eastern cities, J. Air Waste Manage., 56, 500-511, 2006.

Friedrich, R.: Improving and applying methods for the calculation of natural and biogenic emissions and assessment of impacts to the air quality, Final project activity report 2007, available at: http://natair.ier.uni-stuttgart.de/ (last access: March 2011), 2007.

Harrison, R. M., Jones, A. M., and Lawrence, R. G.: A pragmatic mass closure model for airborne particulate matter at urban background and roadside sites, Atmos. Environ. 37, 4927-4933, 2003.

Hoek, G., Meliefste, K., Cyrys, J., Lewné, M., Bellander, T., Brauer, M., Fischer, P., Gehring, U., Heinrich, J., van Vliet, P., Brunekreef, B.: Spatial variability of fine particle concentrations in three European areas, Atmos. Environ. 36, 4077-4088, 2002.

Hoelzemann, J., Schultz, M. G., Brasseur, G. P., Granier, C., and Simon, M.: Global Wildland Fire Emission Model (GWEM): Evaluating the use of global area burnt satellite data, J. Geophys. Res. 109, D14S04, doi:10.1029/2003JD003666, 2004.

Hopke, P. K., Liu, C., and Rubin, D. B.: Multiple imputation for multivariate data with missing and below-threshold measurements: time-series concentrations of pollutants in the arctic, Biometrics 57, 22-33, 2001.

Korcz, M., Fudała, J. and Kliś, C.: Estimation of wind blown dust emissions in Europe and its vicinity, Atmos. Environ. 43, 14101420, 2009.

Matthijsen, J., Jimmink, B., De Leeuw, F., and Smeets, W.: Attainability of $\mathrm{PM}_{2.5}$ air quality standards, situation for the Netherlands in a European context, PBL report 500099015, Bilthoven, the Netherlands, 2009.

Mazzei, F., D’Alessandro, A., Lucarelli, F., Nava, S., Prati, P., Valli, G. and Vecchi, R.: Characterization of particulate matter sources in an urban environment, Sci. Total Environ. 41, 81-89, 2008.

Meijer, E., van Velthoven, P., Brunner, D., Huntrieser, H., and Kelder, H.: Improvement and evaluation of the parameterization of nitrogen oxide production by lightning, Phys. Chem. Earth, 26, 557-583, 2001.

Mooibroek, D., Schaap, M., Weijers, E. P., and Hoogerbrugge, R.: Source apportionment and spatial variability of $\mathrm{PM}_{2.5}$ using measurements at five sites in the Netherlands, Atmos. Environ., submitted, 2010.

Pope, C. A., Thun, M., Namboodiri, M., Dockery, D., Evans, J., Speizer, F., and Heath, C.: Particulate air pollution as a predictor of mortality in a prospective study of US adults, Am. J. Resp. Crit. Care, 151, 669-674, 1995.

Putaud, J.-P., Raesa, F., Van Dingenen, R., Bruggemann, E., Facchini, M., Decesari, S., Fuzzi, S., Gehrig, R., Hüglin, C., Laj, P., Lorbeer, G., Maenhaut, W., Mihalopoulos, N., Mueller,K., Querol, X., Rodriguez, S., Schneider, J., Spindler, G., Ten Brink, H., Torseth, K., and Wiedensohler, A.: A European aerosol phenomenology - 2: Chemical characteristics of particulate matter at kerbside, urban, rural and background locations in Europe, Atmos. Environ., 38, 2579-2595, 2004.

Putaud, J.-P., Van Dingenen, R., Alastuey, A., H. Bauer, Birmili, W., Cyrys, J. , Flentje, H., Fuzzi, S., Gehrig, R., Hansson, H.C. , Harrison, R.M., Herrmann, H., Hitzenberger, R., Hüglin, C., Jones, A. M., Kasper-Giebl, A., Kiss, G., Kousa, A., Kuhlbusch, T. A. J., Löschau, G., Maenhaut, W., Molnar, A., Moreno, T., Pekkanen, J. , Perrino, C., Pitz, M., Puxbaum, H., Querol, X.,
Rodriguez, S., Salma, I., Schwarz, J., Smolik, J., Schneider, G., Spindler, H., Ten Brink, Tursic, J. J., Viana, M., Wiedensohler, A., and Raes, F.: A European aerosol phenomenology - 3: Physical and chemical characteristics of particulate matter from 60 rural, urban, and kerbside sites across Europe, Atmos. Environ. 44, 1308-1320, 2009.

Sánchez-Ochoa, A., Kasper-Giebl, A., Puxbaum, H., Gelencser, A., Legrand, M., and Pio, C.A.: Concentration of atmospheric cellulose: A proxy for plant debris across a west-east transect over Europe, J. Geophys. Res.-Atmos., 112, D23S08, doi:10.1029/2006JD008180, 2007.

Salvador, P., Arti, B., Querol, X., Alastuey, A., adn Costoya, M.: Characterisation of local and external contributions of atmospheric particulate matter at a background coastal site, Atmos. Environ. 41, 1-17, 2007.

Schaap, M. and Denier van der Gon, H. A. C.: On the variability of Black Smoke and carbonaceous aerosols in the Netherlands, Atmos. Environ., 41, 5908-5920, 2007.

Schaap, M., Spindler, G., Schulz, M., Acker, K., Maenhaut, W., Berner, A., Wieprecht, W., Streit, N., Mueller, K., Brüggemann, E., Putaud, J.-P., Puxbaum, H., Baltensperger, U., and Ten Brink H. M.: Artefacts in the sampling of nitrate studied in the "INTERCOMP" campaigns of EUROTRAC-AEROSOL, Atmos. Environ. 38, 6487-6496, 2004.

Schaap, M., Manders, A. M. M., Hendriks, E. C. J., Cnossen, J. M., Segers, A. J. S., Denier van der Gon, H. A. C., Jozwicka, M., Sauter, F. J., Velders, G. J. M., Matthijsen, J., and Builtjes, P. J. H.: Regional modelling of particulate matter for the Netherlands, PBL Report 500099006, Bilthoven, the Netherlands, 2009.

Schaap, M., Weijers, E. P., Mooibroek, D., Nguyen, L., and Hoogerbrugge, R.: Composition and origin of particulate matter in the Netherlands, PBL report 500099007, Bilthoven, the Netherlands, 2010.

Sillanpää, M., Hillama, R., Saarikoski, S., Frey, A., Pennanen, A., Makkonen, U., Spolnik, Z., Van Grieken, R., Braniš, M., Brunekreef, B., Chalbot, M.-C., Kuhlbusch, Th., Sunyer, J., Kerminen, V.-M., Kulmala M., and Salonen, R. O.: Chemical composition and mass closure of particulate matter at six urban sites in Europe, Atmos. Environ., 40, 212-223, 2006.

Simpson, D., Winiwarter, W., Börjesson, G., Cinderby, S., Ferreiro, A., Guenther, A., Hewitt, N., Janson, R., Khalil, M. A. K., Owen, S., Pierce, T., Puxbaum, H., Shearer, M., Skiba, U., Steinbrecher, R., Tarrason, L,. and Öquist, M. G.: Inventorying emissions from nature in Europe, J. Geophys. Res. 104, 8113-8152, 1999.

Simpson, D., Yttri, K. E., Klimont, Z., Kupiainen, K., Caseiro, A., Gelencsér, A., Pio, C. A., Puxbaum, H., and Legrand, M.: Modeling carbonaceous aerosol over Europe: Analysis of the CARBOSOL and EMEP EC/OC campaigns, J. Geophys. Res.Atmos., 112, D23S14, doi:10.1029/2006JD008158, 2007.

Ten Brink, H. M., Maenhaut, W., Hitzenberger, R., Gnauk, T., Spindler, G., Even, A., Chi, X., Bauer, H., Puxbaum, H., Putaud, J.-P., Tursic J., and Berner A.: INTERCOMP2000: the comparability of methods in use in Europe for measuring the carbon content of aerosol, Atmos. Environ., 38, 6507-6519, 2004.

Ten Brink, H. M., Weijers, E. P., Van Arkel, F. Th., and De Jonge, D.: Carbon (EC/OC) concentrations as derived from routine PM measurements in the Netherlands, PBL Report 500099005, Bilthoven, the Netherlands, 2009.

Ten Brink, H. M., Weijers, E. P., Röckmann, T., and Dusek, U.: ${ }^{14} \mathrm{C}$ 
analysis of filter samples for source apportionment of PM in the Netherlands, ECN Report E-10-005, 2010.

van der Hoek, K. W.: Estimating ammonia emission factors in Europe: Summary of the work of the UNECE ammonia expert panel, Atmos. Environ., 32, 315-316, 1998.

Viana, M., Kuhlbusch, T. A. J., Querol, X., Alastuey, A., Harrison, R. M., Hopke, P. K., Winiwarter, W., Vallius, M., Szidat, S., Prévôt, A. S. H., Hüglin, C., Bloemen, H., Wåhlin, P., Vecchi, R., Miranda, A. I., Kasper-Giebl, A., Maenhaut, W., and Hitzenberger, R.: Source apportionment of particulate matter in Europe: A review of methods and results, J. Aerosol Sci. 39, 827-849, 2008.
Visser, H., Buringh, E., and van Breugel, P. B.: Composition and origin of airborne particulate matter in The Netherlands. National Institute for Public Helath and the Environment, RIVM, The Netherlands, Report 650010029, 2001.

Weijers, E. P., Sahan, E., Brink, H. M., ten, Schaap, M., Matthijsen, J., Otjes, R. P., and van Arkel, F.: Contribution of secondary inorganic aerosols to $\mathrm{PM}_{10}$ and $\mathrm{PM}_{2.5}$ in the Netherlands; measurement and modeling results, PBL report 500099006, Bilthoven, 2010 . 